\title{
Concentrations and isotope compositions of particle-bound mercury in a severe haze episode in Tianjin, China
}

\author{
KE ZHANG ${ }^{1}$, WANG ZHENG ${ }^{2}$, SHENGLIU YUAN ${ }^{1,3}$, \\ HONGMING CAI ${ }^{1}$, DAVID AU YANG ${ }^{4}$, WANGCAI SHUAI ${ }^{1}$, \\ ZHONGWEI WANG ${ }^{4}$ AND JIUBIN CHEN $^{2}$ \\ ${ }^{1}$ School of Earth System Science, Tianjin University \\ ${ }^{2}$ Tianjin University \\ ${ }^{3}$ Chemistry Department, Trent University \\ ${ }^{4}$ Chinese Academy of Sciences \\ Presenting Author: zhangke@tju.edu.cn
}

Haze episodes often lead to atmospheric $\mathrm{Hg}$ pollution because the elevated concentration of particles could enhance the adsorption of regionally emitted $\mathrm{Hg}^{2+}$ and the catalytic oxidation of gaseous $\mathrm{Hg}^{0}$, which directly influences the transport and fate of atmospheric $\mathrm{Hg}$. Thus particle-bound $\mathrm{Hg}$ (PBM) does not necessarily reflect primary anthropogenic emission, but could also reflect atmospheric transformations of $\mathrm{Hg}$. To further reveal the sources and processes of PBM under severe haze conditions, total suspended particles (TSP), $\mathrm{PM}_{10}$ and $\mathrm{PM}_{2.5}$ samples were simultaneously collected during day and night respectively in Tianjin, Northern China from January 8th to 15th, 2019, when the highest daily average concentration of TSP was up to 600 $\mu \mathrm{g} / \mathrm{m}^{3}$. Hg concentrations and isotopic compositions were analyzed, together with other geochemical parameters and meterological data. For all samples, the total $\mathrm{Hg}$ concentration increased when haze pollution aggravated, ranging from 0.42 $\mu \mathrm{g} / \mathrm{g}$ to $3.83 \mu \mathrm{g} / \mathrm{g}$, and more than three-quarters of PBM existed in the particle size range less than $2.5 \mu \mathrm{m}$. Most samples display significantly negative mass dependent fractionation, positive mass independent fractionation (MIF) for odd mass isotopes $\left(\Delta^{199} \mathrm{Hg}\right.$ ), and slightly positive MIF for even mass isotopes $\left(\Delta^{200} \mathrm{Hg}\right.$ ). Among them, $\Delta^{199} \mathrm{Hg}$ of $\mathrm{Hg}_{\mathrm{PM} 2.5}$ and $\mathrm{Hg}_{\mathrm{TSP}}$ show diurnal variation, which is generally consistent with those day and night $\mathrm{PM}_{2.5}$ samples reported by Huang et al. [1]. The difference is that our samples show the highest $\Delta{ }^{199} \mathrm{Hg}$ when haze pollution peaked. The $\mathrm{Hg}$ isotope results in our particulate samples suggest that there were likely multiple sources of PBM with variable contributions, including coal combustion, smelting, cement production and biomass burning. Furthermore, our data also suggest that PBM has undergone photoreduction to different extents after emission from primary sources during this severe haze episode. However, the mechanism of PBM photoreduction under haze conditions is still investigation.

[1] Huang, Q., Chen, J., Huang, W., et al. (2019), ACP 19, 315-325. 